\title{
Assessment of Performance Index of Emergency Department in a Hospital in Tehran, Iran
}

\author{
Mojtaba Ghavidel ${ }^{1}$, Hamid Javadzadeh², Mohsen Saberi Esfeedvajani ${ }^{*}$, Maryam Emami Meybodi ${ }^{4}$ \\ ${ }^{1}$ Faculty of Medicine, Baqiyatallah University of Medical Sciences, Tehran, Iran \\ 2Department of Emergency Medicine, Faculty of Medicine, Baqiyatallah University of Medical Sciences, Tehran, Iran \\ ${ }^{3}$ Medicine, Quran and Hadith Research Center \& Department of Community Medicine, Faculty of Medicine, Baqiyatallah \\ University of Medical Sciences, Tehran, Iran \\ ${ }^{4}$ Tehran University of Medical Sciences, Tehran, Iran
}

*Corresponding Author: Mohsen Saberi Esfeedvajani, M.D., Associate Professor, Medicine, Quran and Hadith Research Center \& Department of Community Medicine, Faculty of Medicine, Baqiyatallah University of Medical Sciences, Tehran, Iran. Tel: +98-21-81263617, Email: drsaberihaji@gmail.com

Received December 6, 2016; Accepted March 15, 2017; Online Published May 24, 2017

\begin{abstract}
Background: Evaluating and monitoring the performance of emergency departments (EDs) are steps in one of the most important processes to improving the efficiency of hospitals. Indicators such as patient wait time until being visited by a doctor, patient wait time from the order until admission, percentage of patients with a determined order, time of conversion of a patient's condition, time of physical exit of discharged patients from ED, percentage of discharge with personal responsibility, and percentage of unsuccessful cardiopulmonary resuscitation (CPR) have been used for this measurement. Objective: The current study compared performance indicators in Baqiyatallah Hospital from December 2011 to June 2015. Methods: For this cross-sectional, retrospective study, the study population contained completed checklists of performance indicators in Baqiyatallah Hospital's ED from December 2011 to June 2015. Five indicators were selected and analyzed using SPSS software and $\chi^{2}$ and analysis of variance (ANOVA) tests.

Results: The mean ED performance indicators showed that $71.72 \% \pm 13.29$ of patients were determined within 6 hours, $57.53 \% \pm 27.54$ were discharged within 12 hours of ED admission, $63.36 \% \pm 12.74$ had unsuccessful CPR, $4.57 \% \pm 0.84$ left the ED with personal responsibility, mean duration of triage level 1 was 1 minute \pm 0.55 , mean duration of triage level 2 was 2.83 minutes \pm 0.48 , mean duration of triage level 3 was $8.58 \pm 13.09$ minutes, mean duration of triage level 4 was 19.24 minutes \pm 13.24 , and mean duration of triage level 5 was 40.53 minutes \pm 11.66 . Statistical analysis of the results showed significant differences in all indicators.

Conclusion: The general performance of the Baqiyatallah Hospital ED was estimated to be favorable, and the general process of change during the study was positive compared to previous years; however, the level and quality of services can be increased through some proposed means.

Keywords: Cardiopulmonary resuscitation, Performance index, Indicators and reagents, Triage
\end{abstract}

\section{Background}

Hospitals are an important part of healthcare services. The proper performance of a hospital plays a significant role in the recovery of patients and their return to society. The smallest error in the management of problems will lead to multiple results and problems. ${ }^{1}$ The emergency department (ED) is the heart of the hospital, and regular turnover in this department can save the lives of numerous people. A hospital is not active no function appropriately as an ideal treatment center without an ED; if a hospital has no ED, it will be affected by major defects. ${ }^{2}$ Assessing and monitoring performance in the ED is the most important process. Specifying quantitative standards and a range of valid and significant indicators in the ED are considered the uttermost activities in this process. ${ }^{3}$ Hospital indicators are important indicators of hospital performance in a variety of fields. Therefore, full attention to these markers is essential. As the status of indicators of a hospital reflect the hospital's performance, more concentration on these indicators will clarify the strengths and weaknesses. Moreover, indicators related to the ED show performance in various areas. ${ }^{4}$

Iranian and foreign studies have provided a number of indicators for the application of these indicators in a hospital's ED, ${ }^{5}$ the most important of which, as presented by Welch et al, ${ }^{6}$ include the wait time of the patient at the ED until admission, the wait time of the patient until visited by a doctor, the wait time of the patient from admission in the ED to doctor's order, the duration of changing the patients' condition, duration of physical exit of patients

Copyright (C) 2017 The Hospital Practices and Research. This is an open-access article distributed under the terms of the Creative Commons Attribution License (http://creativecommons.org/licenses/by/4.0), which permits unrestricted use, distribution, and reproduction in any medium, provided the original work is properly cited. 
discharged from the ED, duration from order until referral of the patient, duration of obtaining admission from the target hospital, duration of the referred or admitted patient leaving the hospital's ED, duration of performing lab tests and preparation of the lab tests and $\mathrm{x}$-ray results since the doctor's orders. A study in Imam Khomeini hospital by Maleki et al in Arak evaluated indicators, such as mean wait time in each triage level, ${ }^{1-5}$ wait time per dissatisfied patient, and index for mean wait time of patients in queue (doctors, nurses, lab tests, chest, cashier, for access to rooms, admission, triage 1 and 2) in minutes, and mean number of patients in queue (doctors, nurses, lab, cashier, rooms, admission, triage 1 and 2).?

Health indicators are numerous, but few of them are measured correctly. Therefore, it is necessary to identify and measure the prioritized indicators. ${ }^{8}$ To measure prioritized indicators in the $\mathrm{ED}$, five indicators were selected by the Ministry of Health as admission indicators to be measured in the first step and at the macro-ministerial level.

\section{Objective}

This study aimed to determine the ED's performance of Baghiyatollah hospital, considering the establishment of clinical governance in the hospital, from the beginning of December 2011 until the end of June 2015, all seasons and months, to recognize its status and the possibility of planning to improve the situation.

\section{Methods}

In this cross-sectional and retrospective study, the population consisted of performance indicators of Baghiyatollah hospital. The sample size consisted of checklists at the Baghiyatollah hospital ED completed from December 2011 until June 2015. The inclusion criteria consisted of presence of medical records at ED during the study time, and the exclusion criteria consisted of incomplete or non-eligible medical records.

To measure the priority indicators, a meeting was held with experts and specialists, and 5 indicators that had been selected as high priority at the first level and were introduced at the macro-ministerial level by the Ministry of Health were chosen for this study (Table 1).

SPSS version 21 statistical software was used to analyze the data. Quantitative variables were reported by mean and standard deviation and qualitative variables by percent and frequency. $\chi^{2}$ and analysis of variance (ANOVA) tests were used for analysis.

Due to the ethical considerations, the information of the medical records of all patients admitted to Baghiyatollah hospital was kept confidential.

\section{Results}

The hospital's ED performance indicators in the study years are shown in Table 2. Accordingly, mean and standard deviation (SD) of ED performance are as follows: percentage of patients determined within 6 hours was $71.72 \% \pm 13.29$; percentage of patients discharged within 12 hours of ED admission was $57.53 \% \pm 27.54$; percentage of unsuccessful CPR attempts was $63.36 \% \pm 12.74$; percentage of patients discharged from ED with personal responsibility was $4.57 \% \pm 0.84$; mean duration of triage level 1 was 1 minute \pm 0.55 , level 2 was 2.83 minutes \pm 0.48 , level 3 was $8.58 \pm 13.09$ minutes, level 4 was 19.24 minutes \pm 13.24 , and level 5 was 40.53 minutes \pm 11.66 .

Statistical analysis of the results showed significant differences in all indicators during the five study years at Baghiyatollah Hospital (Table 3).

Statistical analysis for the mean value of each index in each year compared with other years can be seen in Table 4 .

Analysis of the results based on the 4 seasons showed that all the hospital's performance indicators during the various seasons from 2011 to the summer of 2015 were not significantly different.

Analysis of the 12 months during the study period showed no significant difference in all the hospital's performance indicators during different months of 2011 to the summer of 2015.

\section{Discussion}

The index of percentage of patients determined within 6 hours had a minimum of 52, maximum of 94 , and a mean of $72.71 \%$ in the present study. These figures were lower than those determined in the study by Baratloo et al in Shohada hospital's ED in 2012 which reported this index at about 93\%. ${ }^{9}$ Asadi et al determined that the status of Poursina hospital's ED in Rasht improved to $23.4 \%$ after emergency medicine specialists were added; that figure is about $50 \%$ lower than that of the present study..$^{10}$ Also, in a study at Metropolitan hospital in Australia over a period of 12 months, the percentage of patients who were determined during 6 hours was on average $78 \%$, a figure that is almost consistent with the present study. ${ }^{11}$

Table 1. The Studied Indicators

\begin{tabular}{lll}
\hline & Index & Scientific Description \\
\hline 1 & $\begin{array}{l}\text { Percentage of patients determined within } \\
6 \mathrm{~h}\end{array}$ & $\begin{array}{l}\text { Proportion of patients temporarily admitted to the ED and determined } \\
\text { within } 6 \mathrm{~h} \text { to all patients temporarily admitted to the ED in a given period }\end{array}$ \\
$\begin{array}{l}\text { Percentage of patients discharged from } \\
\text { the ED within } 12 \mathrm{~h}\end{array}$ & $\begin{array}{l}\text { Proportion of patients temporarily admitted to the ED who exited the ED } \\
\text { within } 12 \mathrm{~h} \text { of arrival to total patients temporarily admitted to the ED } \\
\text { Proportion of unsuccessful CPR in ED to all CPR cases done in a period of } \\
\text { time }\end{array}$ \\
$\begin{array}{ll}\text { Percentage of unsuccessful CPR attempts } \\
\text { Percentage of discharge with personal } \\
\text { responsibility }\end{array}$ & $\begin{array}{l}\text { Proportion of patients discharged with personal responsibility, against } \\
\text { medical advice (AMA), to all patients temporarily admitted to the ED } \\
\text { Mean duration of each triage level }\end{array}$ & $\begin{array}{l}\text { Mean duration between initial triage by the nurse and first medical visit } \\
\text { according to the triage level }\end{array}$ \\
\hline
\end{tabular}

Abbreviation: ED, emergency department. 
Table 2. Values of Baghiyatollah Hospital's Performance Indicators During Different Months of 2011 to the Summer of 2015

\begin{tabular}{lccccc}
\hline Indicators & Number & Minimum & Maximum & Mean & SD \\
\hline Patients determined during 6 h & 43 & 52 & 94 & 71.72 & 13.29 \\
Patients discharged from ED within 12 h & 43 & 19 & 85 & 57.53 & 27.54 \\
Unsuccessful CPR attempts & 43 & 34 & 82 & 63.36 & 12.74 \\
Discharge with personal responsibility & 43 & 1.8 & 5.84 & 4.57 & 0.84 \\
The number of admitted patients & 43 & 1562 & 2217 & 1888.58 & 135.5 \\
Triage level 1 & 43 & 0.28 & 1.87 & 1 & 0.55 \\
Triage level 2 & 43 & 2 & 3.75 & 2.83 & 0.48 \\
Triage level 3 & 43 & 2.92 & 29 & $13: 09$ & 8.58 \\
Triage level 4 & 43 & 5.6 & 40 & $19: 24$ & $13: 24$ \\
Triage level 5 & 27 & 15 & 82.16 & 40.53 & 11.66 \\
\hline
\end{tabular}

Abbreviations: ED, emergency department; SD, Standard deviation.

Table 3. Analytical Results of Baghiyatollah Hospital's Performance Indicators During Different Months of 2011 to the Summer of 2015

\begin{tabular}{|c|c|c|c|c|c|c|c|c|c|c|c|}
\hline \multirow{2}{*}{ Indicators } & \multicolumn{2}{|c|}{2011} & \multicolumn{2}{|c|}{2012} & \multicolumn{2}{|c|}{2013} & \multicolumn{2}{|c|}{2014} & \multicolumn{2}{|c|}{2015} & \multirow{2}{*}{$\boldsymbol{P}$} \\
\hline & Mean & SD & Mean & SD & Mean & SD & Mean & SD & Mean & SD & \\
\hline Patients determined during $6 \mathrm{~h}$ & 86.2 & 2.62 & 85.2 & 7.94 & 57 & 2.96 & 67.4 & 8.18 & 74 & 3.6 & .000 \\
\hline Patients discharged from ED within $12 \mathrm{~h}$ & 21.7 & 1.25 & 22.5 & 1.84 & 77 & 3.82 & 79 & 2.74 & 80.6 & 3.05 & .000 \\
\hline Unsuccessful CPR attempts & 74.5 & 2.38 & 74.5 & 5.72 & 62.2 & 12.2 & 53.7 & 8.48 & 46.3 & 2.08 & .000 \\
\hline Discharge with personal responsibility & 2.31 & 0.37 & 4.82 & 0.47 & 4.64 & 0.42 & 5.02 & 0.34 & 4.53 & 0.08 & .000 \\
\hline Number of patients admitted & 1627 & 50.3 & 1807 & 84.6 & 1950 & 48.2 & 1977 & 108 & 1963 & 103 & .000 \\
\hline Triage level 1 & 0.90 & 0.03 & 0.31 & 0.03 & 1.14 & 0.51 & 1.48 & 0.30 & 1.39 & 0.02 & .000 \\
\hline Triage level 2 & 3.12 & 0.17 & 2.48 & 0.20 & 3.10 & 0.45 & 2.86 & 0.62 & 2.66 & 0.28 & .012 \\
\hline Triage level 3 & 5.47 & 0.58 & 4.60 & 0.60 & 16 & 8.41 & 20.2 & 6.39 & 16.6 & 1.52 & .000 \\
\hline Triage level 4 & 6.85 & 0.86 & 5.74 & 0.13 & 24.5 & 12.3 & 30.1 & 9.58 & 25 & 1.73 & .000 \\
\hline Triage level 5 & 0 & 0 & 0 & 0 & 40.2 & 8.93 & 36.4 & 14.05 & 29.66 & 19.28 & .076 \\
\hline
\end{tabular}

Abbreviations: ED, emergency department; SD, Standard deviation.

The percentage of patients discharged from the ED within 12 hours in the present study was a minimum of 19 , maximum of 85 , and a mean of $57.53 \%$. These figures are lower than those of Shohadaye Tajrish and Australia's Metropolitan hospitals..$^{11,12}$

The percentage of unsuccessful CPR attempts in the present study were a minimum of 34 , maximum of $82 \%$, and mean of $63.36 \%$, which were consistent with the study of Baharloo Hospital's ED that estimated it at a rate of $60 \% .^{13}$

The percentage of patients discharged with personal responsibility in the present study were a minimum of $1.8 \%$, maximum of $5.8 \%$, and mean of $4.57 \%$; these figures were significantly better than those of the ED at Shohada hospital that reported it to be about $20 \% \cdot{ }^{12}$ Sanchez et al also studied the effect of the rapid method in the performance of EDs and reported the percentage of patients who left without receiving any ED services was $7.78 \%$ before the rapid method. That is similar to the index in the present study which decreased to $4.06 \%$ after implementation of the rapid method. ${ }^{14}$ The study by Medeiros et al used an image-algorithm guidance for patients and reported the percentages of patients who left without receiving any ED services before and after the implementation of the project at $5.6 \%$ and $2.7 \%$, respectively. The comparison of those results with the results of the present study shows higher rates before the project, and after implementation of the project the index was reduced to half the rate reported in the current study. ${ }^{15}$

The duration of triage level 1 in the present study was a minimum of 0.28 minutes, maximum of 1.87 minutes, and mean of 1 minute; the duration of triage level 2 was a minimum of 2 minutes, maximum of 3.75 minutes, and mean of 2.83 minutes. These results are significantly more favorable than those of the Imam Khomeini hospital in Arak. $^{7}$

The duration of triage level 3 in the present study was a minimum of 2.92 minutes, maximum of 29 minutes, and mean of 13.9 minutes. Compared with the study of Maleki et al in Imam Khomeini hospital of Arak, the duration of this index was lower than scenarios 1 and 2 and higher than scenarios 4 and 5.7

The duration of triage level 4 in the present study was a minimum of 5.6 minutes, maximum of 40 minutes, and an average of 19.24 minutes. These results are much less than the index of about 3 hours reported at Penn State Hershey Medical Center ED. ${ }^{15}$

The duration of triage level 5 in the present study was a minimum of 15 minutes, maximum of 82.16 minutes, and an average of 40.53 minutes. The index at Penn State Hershey Medical Center ED was about twice that of the present study. ${ }^{15}$ However, the rates of all 4 scenarios in the 
Table 4. Pair Comparison of Performance Index of Baghiyatollah Hospital's ED During Different Months of 2011 to the Summer of 2015

\begin{tabular}{|c|c|c|c|c|c|c|}
\hline & $\begin{array}{l}\text { Years of } \\
\text { Study }\end{array}$ & $\begin{array}{c}\text { Patients Determined } \\
\text { During } 6 \mathrm{~h}\end{array}$ & $\begin{array}{l}\text { Patients Discharged } \\
\text { From ED Within } 12 \mathrm{~h}\end{array}$ & $\begin{array}{c}\text { Unsuccessful CPR } \\
\text { Attempts }\end{array}$ & $\begin{array}{c}\text { Discharge With } \\
\text { Personal Responsibility }\end{array}$ & Triage Level \\
\hline \multirow{4}{*}{2011} & 2012 & 0.999 & 0.992 & 1 & 0.000 & 0.057 \\
\hline & 2013 & 0.000 & 0.000 & 0.220 & 0.000 & 0.804 \\
\hline & 2014 & 0.000 & 0.000 & 0.005 & 0.000 & 0.069 \\
\hline & 2015 & 0.143 & 0.000 & 0.004 & 0.000 & 0.429 \\
\hline \multirow{4}{*}{2012} & 2011 & 0.999 & 0.992 & 1 & 0.000 & 0.057 \\
\hline & 2013 & 0.000 & 0.000 & 0.028 & 0.888 & 0.000 \\
\hline & 2014 & 0.000 & 0.000 & 0.000 & 0.824 & 0.000 \\
\hline & 2015 & 0.143 & 0.000 & 0.000 & 0.873 & 0.000 \\
\hline \multirow{4}{*}{2013} & 2011 & 0.000 & 0.000 & 0.220 & 0.000 & 0.804 \\
\hline & 2012 & 0.000 & 0.000 & 0.028 & 0.888 & 0.000 \\
\hline & 2014 & 0.010 & 0.565 & 0.229 & 0.284 & 0.184 \\
\hline & 2015 & 0.007 & 0.440 & 105 & 0.996 & 0.833 \\
\hline \multirow{4}{*}{2014} & 2011 & 0.000 & 0.000 & 0.005 & 0.000 & 0.069 \\
\hline & 2012 & 0.000 & 0.000 & 0.000 & 0.824 & 0.000 \\
\hline & 2013 & 0.010 & 0.565 & 0.229 & 0.284 & 0.184 \\
\hline & 2015 & 0.646 & 0.943 & 0.775 & 0.483 & 0.996 \\
\hline \multirow{4}{*}{2015} & 2011 & 0.207 & 0.000 & 0.004 & 0.000 & 0.429 \\
\hline & 2012 & 0.143 & 0.000 & 0.000 & 0.873 & 0.000 \\
\hline & 2013 & 0.007 & 0.440 & 105 & 0.996 & 0.833 \\
\hline & 2014 & 0.646 & 0.943 & 0.775 & 0.483 & 0.996 \\
\hline
\end{tabular}

Abbreviation: ED, emergency department.

present study were worse and more unfavorable than those of Imam Khomeini hospital, Arak. ${ }^{7}$

The international literature have mentioned the mean standard triage at about 28 minutes, so the status of Baghiyatollah hospital's ED is considered desirable in this respect. ${ }^{16}$

The index of patients determined within 6 hours in 2012 compared to the first year of the study had a slightly steep downward slope. This decline continued in 2013 and decreased about $30 \%$ compared to the previous 2 years. This index had an increasing trend in 2014 compared to the previous years, and the progression continued until 2015; however, the index was lower compared to the first years of data collection.

The percentage of patients discharged from the ED within 12 hours was very low in the first year of the study, and it continued without improvement in 2012. However, the index percentage increased about $50 \%$ with a considerable and stunning difference that was maintained until 2014-2015.

The percentage of unsuccessful CPR attempts was considerable and experienced no change in 2011 and 2012. It declined in 2013, and the decline continued in the following years so that it fell below 50\% in 2015 .

The percentage of patients discharged with personal responsibility in 2012 had nearly doubled compared with the first year of the project; no adverse changes were observed in the following years, and the rate remained at less than $5 \%$ on average.

The number of patients admitted to the hospital's ED had an increasing trend during 2011 to 2015 and increased each year compared to the previous year.
The duration of triage in Baghiyatollah hospital's ED declined in 2012 to about 3 times lower than in the first year of the project, but the duration of triage increased again in 2013 and reached a higher level than the first year of the project (more than 1 minute). This upward trend continued in the years 2014-2015.

Although the general situation at Baghiyatollah hospital in terms of performance index is estimated as optimal and the general trend of changes was more positive during the study years than in the past, ${ }^{17}$ the level and quality of services can be improved. For example, the study of Medeiros et al used image algorithms to guide patients at Penn State Hershey Medical Center's ED, and the authors concluded that this model has been effective in improving treatment performance of the ED. ${ }^{15}$

In other studies around the world, several indicators such as the duration of wait time of the patient from entrance until admission at ED, patient wait time until doctor's visit, patient wait time from admission at ED since doctor's order, the duration of changing the patients' condition, duration of physical exit of patients discharged from the $\mathrm{ED}$, duration from order until referral of patient, duration of obtaining admission from the target hospital, duration of the referred or admitted patient leaving the hospital's $\mathrm{ED}$, and duration of performance and result preparation of lab tests and $\mathrm{x}$-ray since the doctor's orders. ${ }^{8,18-20}$ Therefore, further studies are required in this area to clarify the strengths and weaknesses of the ED and define the road ahead to promote improvement.

\section{Conclusion}

According to the results of the present study, some of the 
performance indicators of Baghiyatollah hospital's ED have changed probably because of changes in the management structure of the hospital. Although the Ministry of Health has set no standards for the assessment of ED performance indicators and its role in hospital accreditation is unclear, the assessment of performance indicators can provide corrective and improvement strategies proposed by senior managers of hospitals. One of the challenges in collecting such data is the data extraction for calculation of the indicators, as this data should not be extracted from patients' medical records and should not be calculated manually. Therefore, it is suggested that the basics of creating electronic medical records for patients with the help of IT managers and designers of electronic medical records for patients be considered and given priority of programs

\section{Authors' Contributions}

All authors contributed equally in this study.

\section{Conflict of Interest Disclosures}

No conflicts of interest.

\section{Ethical approval}

This study was approved by Baqiyatallah University of Medical Sciences Ethics Committee.

\section{Acknowledgments}

The author would like to thank the "Clinical Research Development Unit" of Baqiyatallah Hospital for their kind cooperation.

\section{References}

1. Jafari Joneydi N, Sadeghi M, Izadi M, Ranjbar R. Comparison of performance indicators a hospital in Tehran with national standards. Journal of Military Medicine. 2011;12(4):223-228.

2. Slade D, Manidis M, McGregor J, et al. Communicating in hospital emergency departments. Berlin Heidelberg: Springer; 2015. doi:10.1007/978-3-662-46021-4.

3. Wakai A, O'Sullivan R, Staunton P, Walsh C, Hickey F, Plunkett PK. Development of key performance indicators for emergency departments in Ireland using an electronic modified-Delphi consensus approach. European Journal of Emergency Medicine. 2013;20(2):109-14. doi:10.1097/MEJ.0b013e328351e5d8.

4. Murphy A, Wakai A, Walsh C, Cummins F, O'sullivan R. Development of key performance indicators for prehospital emergency care. Emerg Med J. 2016;33(4):286-292. doi:10.1136/emermed-2015-204793.

5. Parmenter D. Key Performance Indicators: Developing, Implementing, and Using Winning KPIs. John Wiley \& Sons; 2015.

6. Welch S, Augustine J, Camargo CA, Reese C. Emergency department performance measures and benchmarking summit. Acad Emerg Med. 2006;13(10):1074-1080.

7. Maleki A, Sajjadi M, Rezaei Khabushan B. Explanation and improvement performance indicators of the emergency system using discrete event simulation (case study: Arak Imam Khomeini (Persian). Journal of Health Information Managment. 2014; 11(1):4-16.

8. Madsen M, Kiuru S, Castrèn M, Kurland L. The level of evidence for emergency department performance indicators: systematic review. Eur J Emerg Med. 2015;22(5):298-305. doi:10.1097/

\section{Research Highlights}

\section{What Is Already Known?}

Although in the past, the need to monitor and evaluate the performance measures has been emphasized for the effective management of EDs at various levels, until the present study, this issue has been neglected in military hospitals, especially the ED of Baghiyatollah hospital.

\section{What This Study Adds?}

This study showed that the performance of the ED at Baghiyatollah hospital, considering the clinical governance at the hospital, from the beginning December 2011 until the end of June 2015 improved in all areas. The hospital's management can be considered as one of the main causes of change in the performance indicators of wards.

\section{MEJ.0000000000000279}

9. Baratloo A, Rahmati F, Foruzanfar M, Hashemi B, Motamedi M, Safari S. Evaluation of emergency department activity. Iran J Emerg Med. 2015;2(1):33-8.

10. Asadi P, Kasmayi VM, Ziaziabari SM, Marzbani BB. Status determination Poursina hospital emergency department patients before and after the implementation of emergency medicine specialists. Iran J Emerg Med. 2014;1(1):28-33.

11. Combs $S$, Chapman R, Bushby A. Evaluation of fast track. Accid Emerg Nurs. 2007;15(1):40-7.

12. Hashemi B, Baratloo A, Forouzafar MM, Motamedi M, Tarkhorani M. Patient satisfaction before and after executing health sector evolution plan. Iran J Emerg Med. 2015;2(3):127133.

13. Alizadeh M, Movahed M, Sadroldini S, Mostafavi A, Fathi $M$. The evaluation of resuscitation results and the factors influencing it in the Baharloo hospital (Persian). Tehran Univ Med J. 2016;74(9):640-644.

14. Sanchez M, Smally AJ, Grant RJ, Jacobs LM. Effects of a fast-track area on emergency department performance. J Emerg Med. 2006;31(1):117-20. doi:10.1016/j.jemermed.2005.08.019.

15. Medeiros DJ, Swenson E, DeFlitch C, editors. Improving patient flow in a hospital emergency department. Proceedings of the 40th Conference on Winter Simulation; 2008.

16. Hing E, Bhuiya FA. Wait Time for Treatment in Hospital Emergency Departments, 2009. US Department of Health and Human Services, Centers for Disease Control and Prevention, National Center for Health Statistics; 2012.

17. Bahadori MK, Mirhashemi SE, Panahi FA, Sh T, Zaboli R, Rezaee M. Structure, process and practices of the emergency unit of hospitals of Baqiyatallah University of Medical Sciences. J Mil Med. 2008;9(4):257-263.

18. Nielsen LM, Kirkegaard H, Østergaard LG, Bovbjerg K, Breinholt K, Maribo T. Comparison of self-reported and performance-based measures of functional ability in elderly patients in an emergency department: implications for selection of clinical outcome measures. BMC Geriatr. 2016;16(1):199. doi:10.1186/s12877-016-0376-1.

19. Sørup CM, Jacobsen P, Forberg JL. Evaluation of emergency department performance-a systematic review on recommended performance and quality-in-care measures. Scand J Trauma Resusc Emerg Med. 2013;21:62. doi:10.1186/1757-7241-2162.

20. Baratloo A, Rahmati F, Forouzanfar MM, Hashemi B, Motamedi M, Safari S. Evaluation of performance indexes of emergency department. Iran J Emerg Med. 2015;2(1):33-38. 